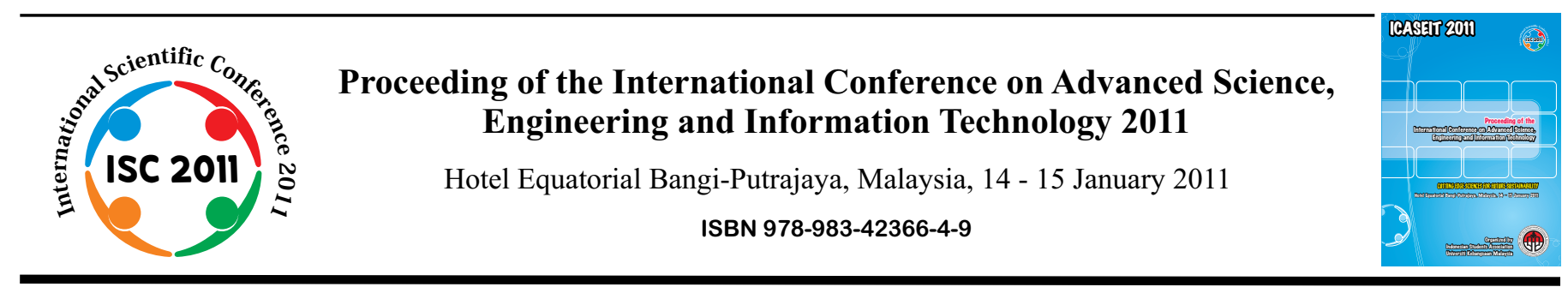

\title{
Nonlinear FE Analysis of Reinforced H.S. Concrete Continuous Beam Strengthened with CFRP Sheet
}

\author{
Majid Mohammed Ali Kadhim \\ Architectural Engineering Department, Babylon University \\ Hillah, Babil, Iraq \\ Tel.:+9647802837310,E-mail: majidce@yahoo.com
}

\begin{abstract}
This paper is focused on the nonlinear finite element analysis of the reinforced high strength concrete continuous beam strength with carbon fiber reinforced polymer sheet. Three full scale continuous beams are analyzed under two points load; the data of analysis are compared with the experimental data provided by Akbarzadeh and Maghsoudi [1]. ANSYS V.11 program is used in FE analysis, the results obtained from analysis give good agreement with experimental result when compared load-deflection responses, ultimate strength, and the crack patterns. The results showed that with increasing the number of layers, the ultimate strength of beams are increase by amount reached $(14 \%)$ for each layer. The failure mode different by increasing number of CFRP sheet layers when the beam strengthened by one layer of CFRP sheet failed by tensile rupture of CFRP sheet, and beam strengthened by more than one layer failed by intermediate crack (IC) debonding of CFRP sheet.
\end{abstract}

Keywords- FE, high strength, continuous beam, CFRP.

\section{INTRODUCTION}

In the last decade, CFRP composite materials have been increasingly employed in the construction industry, mainly in applications dealing with structural strengthening and repair. They are ideally suited for this purpose, due to a combination of the very high stiffness- to-weight and strength-to-weight ratios and an excellent durability in aggressive environments. Indeed, it has been shown, both analytically and experimentally, that the addition of externally bonded FRP composites significantly improves the performance of a structural member, namely its stiffness, load-carrying capacity, durability and fatigue behavior under cyclic load.

Several studies were conducted on the behavior of continuous beam. Although many in situ RC beams are of continuous construction, there has been very little research into the behavior of such beams with external reinforcement [2-5]. In addition, most design guidelines $[6,7]$ were developed for simply supported beams with external fiber reinforced polymer laminates. Ashour et al. and El-Refaie et al. found out that increasing the CFRP sheet length to cover the entire hogging or sagging zones did not prevent the premature failure; further research into the performance of end anchorage techniques is necessary to minimize the risk of this mode of failure. Also, they suggested that, strengthening both the top surface at central support and beam soffit is the most effective arrangement of the CFRP laminates to enhance the beam load capacity $[8,9]$. Akbarzadeh and Maghsoudi tested 6 continuous beams, test results showed that with increasing the number of CFRP sheet layers, the ultimate strength increases, while the ductility, moment redistribution, and ultimate strain of CFRP sheet decrease. Also, new parameters of equivalent stress block were obtained for flexural calculation of RHSC beams. Good agreement between experiment and prediction values was achieved[1]. Up to now, the paper mainly focused the behavior of continuous beam externally strength with CFRP sheet by using finite element method.

\section{NUMERICAL WORK}

\section{A. Finite element model}

In the present study general purpose finite element program (ANSYS V11.0) was used to model the continuous beam. Three elements type was used to built the 3-dimensional model, as listed below

\section{1) Brick element (SOLID65 as denoted in ANSYS [10]):}

This element is used to model the concrete in $3 \mathrm{D}$ and reinforced concrete also. The element has eight nodes three degree of freedom per node translation in $\mathrm{x}, \mathrm{y}$, and $\mathrm{z}$ directions. The most important aspect of this element is the 
treatment of nonlinear material properties. The concrete is capable of cracking (in three orthogonal directions), crushing, plastic deformation, and creep. The rebar are capable of tension and compression, but not shear. They are also capable of plastic deformation and creep [10]. The geometry, node locations, and the coordinate system for this element are shown in Fig. 1.

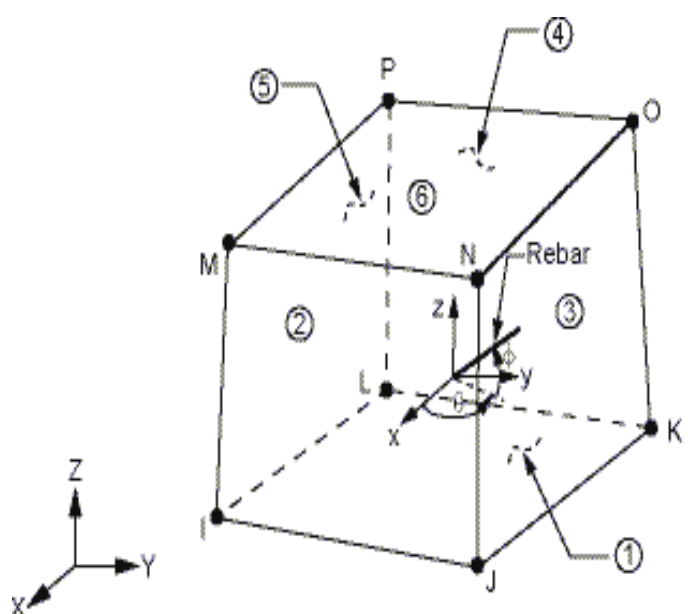

Fig. 1: (SOLID65) Element Geometry [10]

\section{2) Shell element (SHELL41 as denoted in ANSYS):}

The element is defined by four nodes, four thicknesses, a material direction angle and the orthotropic material properties. Orthotropic material directions correspond to the element coordinate directions. The element have membrane stiffness (no bending stiffness) so the element is used to model the CFRP laminate. The element may have variable thickness. The thickness is assumed to vary smoothly over the area of the element, with the thickness input at the four nodes. If the element has a constant thickness, only one thickness (in any node) need be input. If the thickness is not constant, all four thicknesses must be input (for four nodes). The geometry, nodes location, and coordinate of the element are shown in

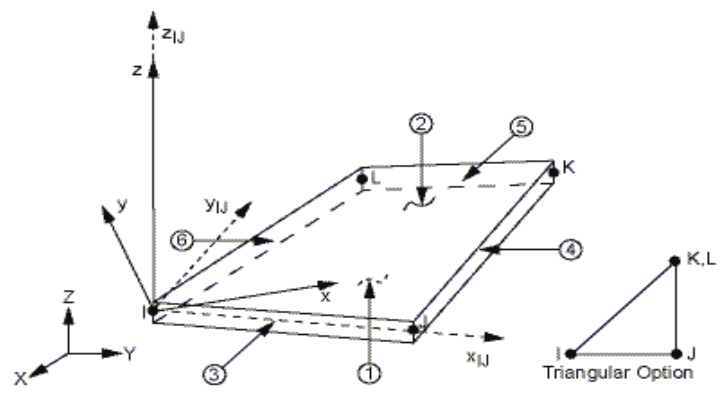

$\mathrm{x}_{\mathrm{IJ}}=$ Element $\mathrm{x}$-axis if ESYS is not supplied

$\mathrm{x}=$ Element $\mathrm{x}$-axis if ESYS is supplied.

Fig. 2: (SELL41) Element Geometry [10]

\section{3) Link element (LINK8 as denoted in ANSYS)}

This element can be used to model trusses, sagging cables, links, springs, etc. The 3-D spar element is a uniaxial tension-compression element with three degrees of freedom at each node: translations in the nodal $\mathrm{x}, \mathrm{y}$, and $\mathrm{z}$ directions. As in a pin-jointed structure, no bending of the element is considered. Plasticity, creep, swelling, stress stiffening, and large deflection capabilities are included [10]. The element is defined by two nodes, cross section area, initial stress, and the material properties, the element geometry, node locations, and the coordinate system for this element is shown in Fig. 3.
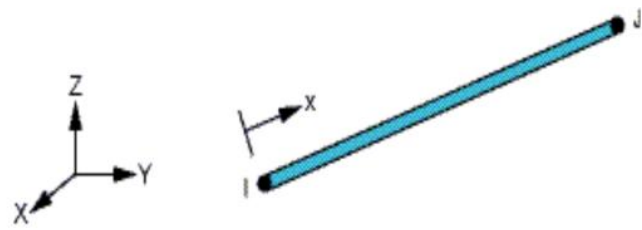

Fig. 3: (LINK8) Element Geometry [10]

\section{B. Material}

The high strength concrete in this study is modelled as nonlinear stress-strain relationship. The nonlinear stressstrain relationship is obtained by tested five specimens as shown in Fig. 4; the average curve shown was used to model concrete in FE analysis.

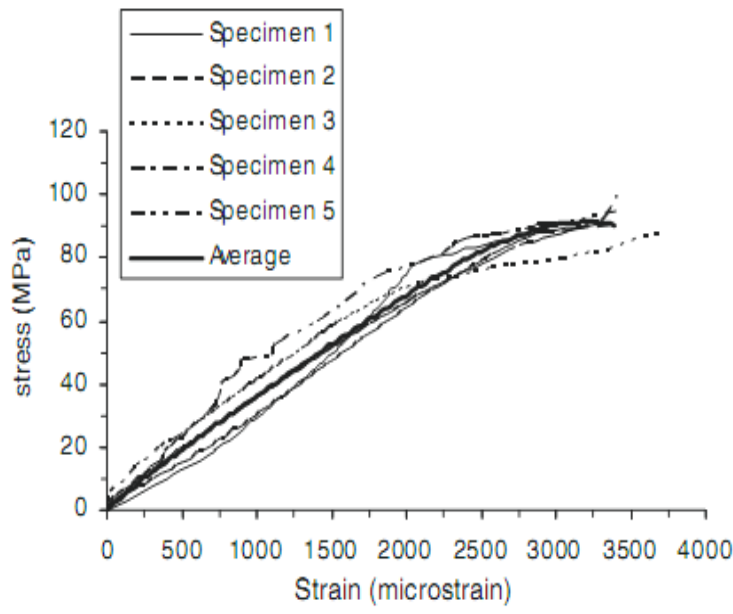

Fig: 4: stress-strain diagram for high strength concrete [1]

In a concrete element (SOLID65), cracking occurs when principle tensile stress lies outside of the failure surface, see Fig. 5, when cracking occurs the elastic modulus of the concrete element is set to zero in the direction parallel to the principle tensile stress direction. Crushing occurs when the principle compressive stress lies outside of the failure surface, after element crashing the elastic modulus of concrete element is set to zero in all directions.

During this study, it was found that if the crushing option is turned on, the concrete elements lies under the load was crashed after several sub steps of load and the local stiffness of member are reduced, so the crushing capability is turned off. 


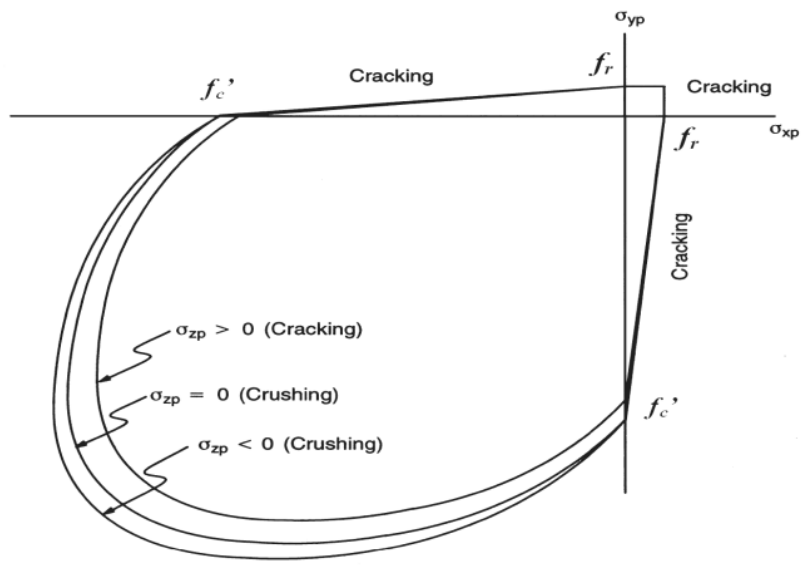

Two bars of diameter $16 \mathrm{~mm}$ were tested by [1] in tensile and the measured yield strength was $412.5 \mathrm{MPa}$, and maximum tensile strength was $626.4 \mathrm{MPa}$. The modulus of elasticity of steel bars was $2 * 105 \mathrm{MPa}$. The Young's modulus and ultimate tensile stress of the CFRP sheet and the properties of epoxies used for bonding the FRP sheets were obtained from the supplier and given in Tables 1 and 2 .

Fig.5: 3D-failure surface for concrete [10]

TABLE 1: MECHANICAL PROPERTIES OF THE CFRP SHEETS.

\begin{tabular}{|c|c|c|c|c|}
\hline $\begin{array}{c}\text { Density } \\
(\mathrm{kg} / \mathrm{cm} 3)\end{array}$ & $\begin{array}{c}\text { Thickness } \\
(\mathrm{mm})\end{array}$ & $\begin{array}{c}\text { Ultimate tensile } \\
\text { stress }(\mathrm{MPa})\end{array}$ & $\begin{array}{c}\text { Young's modulus } \\
(\mathrm{MPa})\end{array}$ & $\begin{array}{c}\text { Ultimat } \\
\text { e strain \% }\end{array}$ \\
\hline 1.81 & 0.11 & 3800 & 242000 & 1.55 \\
\hline
\end{tabular}

TABLE2: DETAILS OF THE TEST SPECIMENS.

\begin{tabular}{|c|c|c|c|c|c|}
\hline \multirow{2}{*}{$\begin{array}{l}\text { Beam } \\
\text { no. }\end{array}$} & $f$\begin{tabular}{c}
$f_{c}(\mathrm{MPa})$ \\
\cline { 3 - 6 }
\end{tabular} & \multicolumn{2}{|c|}{ Positive moment strengthening } & \multicolumn{2}{c|}{ Negative moment strengthening } \\
\cline { 3 - 6 } & No. of layers & $\begin{array}{c}\text { Strengthened } \\
\text { length }(\mathrm{m})\end{array}$ & No. of layers & $\begin{array}{c}\text { Strengthene } \\
\mathrm{d} \text { length }(\mathrm{m})\end{array}$ \\
\hline $\mathrm{SC1}$ & 74.6 & 1 & 2.2 & 1 & 1.8 \\
\hline $\mathrm{SC} 2$ & 74.1 & 2 & 2.2 & 2 & 1.8 \\
\hline $\mathrm{SC} 3$ & 74.4 & 3 & 2.2 & 3 & 1.8 \\
\hline
\end{tabular}
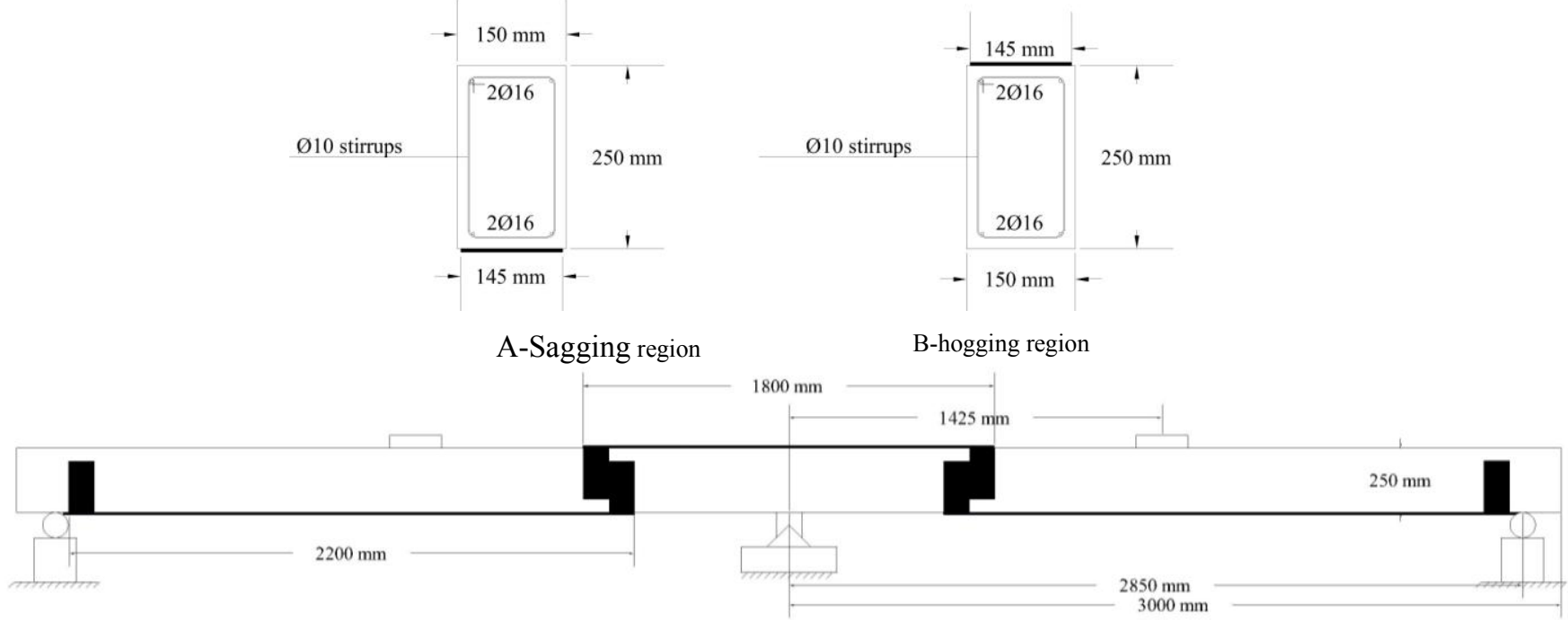

c- Longitudinal profile of beam

Fig. 6 test setup and strengthened RC continuous details [1]

\section{Continuous Beams Description}

The continuous beams analysis in this study was tested by [1], three full-scale continuous beams $(150 * 250 * 6000)$ $\mathrm{mm}$ were tested under two points load, and the all beams were strengthened by CFRP sheet in the region of tension only. The geometry, reinforced arrangement, loads as well as supports arrangements are illustrated in Fig. 6.

The arrangements of CFRP sheet for all beams were same in position but different in number of layers, the CFRP sheet arrangement and numbers of layers for beams are shown in Fig. 6 and table 2 


\section{RESULTS AND DISCUSSION}

The beams described in the previous section analyzed $b$ : using the 3-D nonlinear FE model investigated in thi study. The applied load on the beams is divided in analy into 40 substeps.

\section{A. Load-Deflections Responses}

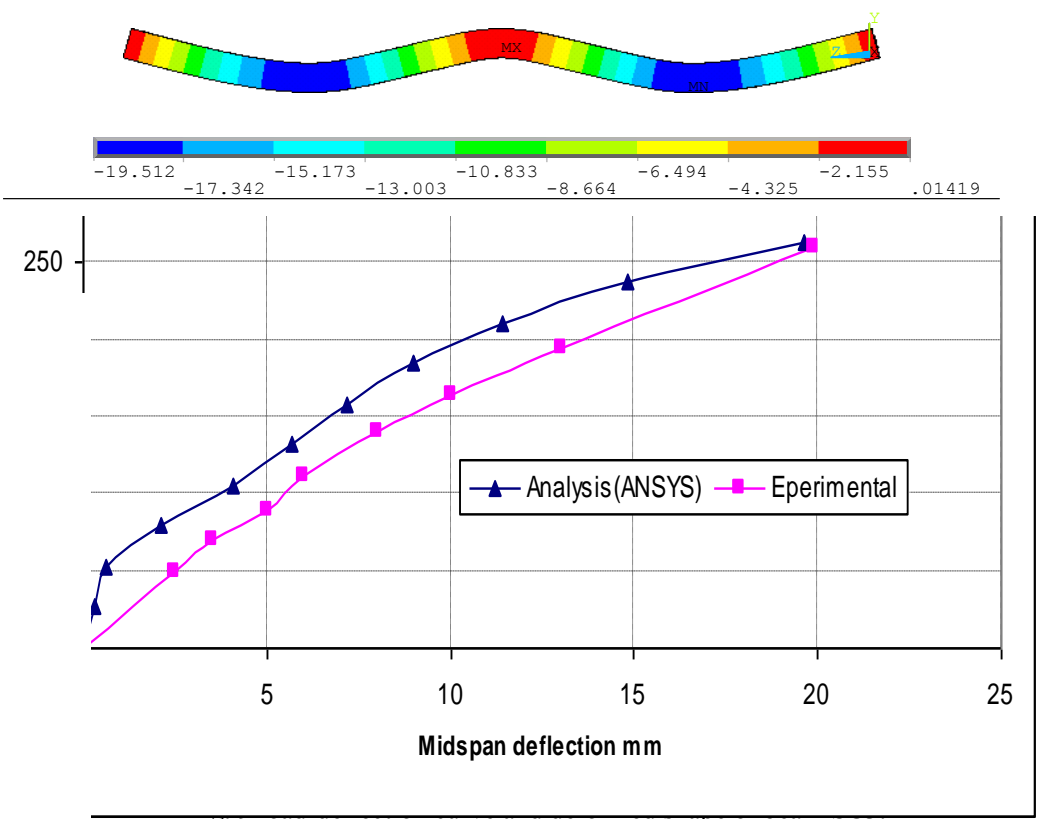

B. Cracks

The cracks in the test beams are concerned in hogging reoinn (central supports) and sagging region (mid-span).

Figs. 10, 11, and 12 show that the crack patterns of ms obtained from finite element analysis are similar sk patterns obtained from experimental work. The in finite element analysis are display by circles at ins of cracks in concrete element. Cracking is shown :les outline in the plane of the crack. Each integration san crack in up of three different planes. The first are shown with a red circle outline, the second crack green circle outline, and the third crack with a blue $\therefore$
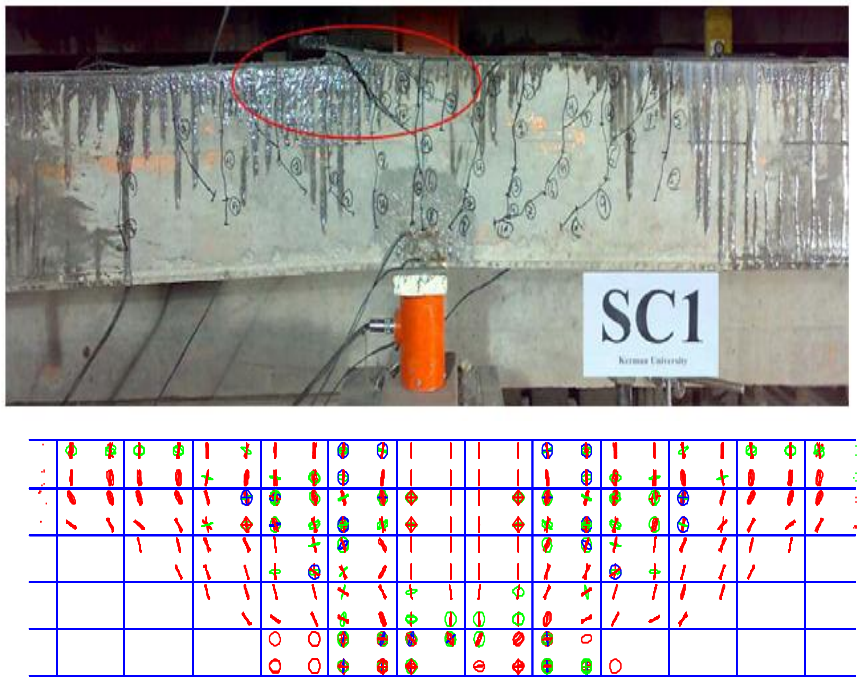

Fig. 10 crack pattern of beam SC1 (comparison between analysis and experimental) 


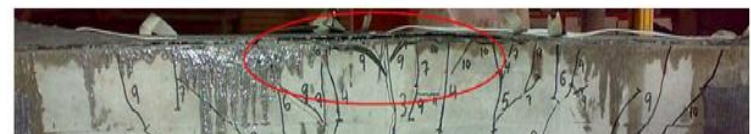

CRACKS AND CRUSHING

$\mathrm{STEP}=1$
$\mathrm{SUB}=20$

JUN 62010

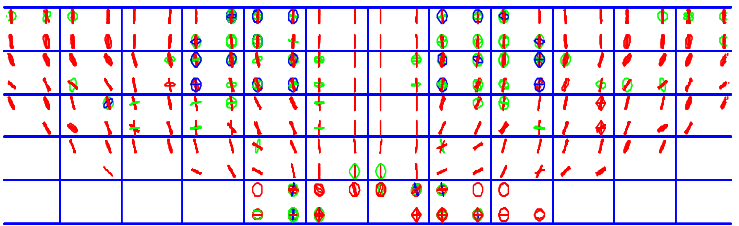

Fig. 11 crack pattern of beam SC2 (comparison between analysis and experimental)

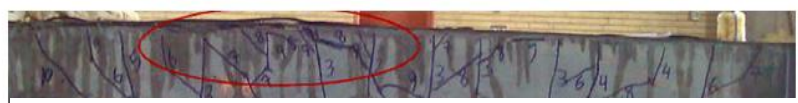

CRACKS AND CRUSHING

$\mathrm{STEP}=1$
$\mathrm{SUB}=20$
$\mathrm{TTY}=1$
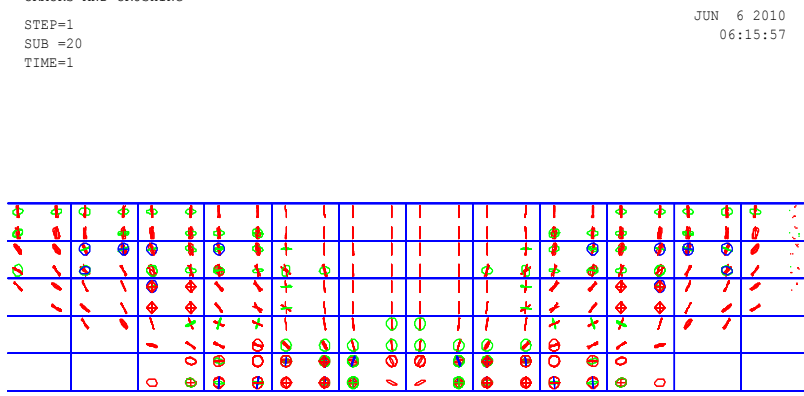

Fig. 12 crack pattern of beam SC3 (comparison between analysis and experimental)

show as follows:

The beam (SC1) failed by tensile rapture in CFRP sheets in the central support by load reached about $(196 \mathrm{kN})$, when beam ( $\mathrm{SC} 2$ and $\mathrm{SC} 3$ ) are failed by intermediate crack (IC) debonding of CFRP sheet in hogging region by load reached about (213 and $257 \mathrm{kN})$ respectively. The beam flexural capacity is increased and therefore more number of flexural cracks are appear in the beam as shown in Figs. 10, 11 , and 12

\section{CONCLUSIONS}

Based on results obtained from the investigation, the following can be concluded:

1. Increasing the number of CFRP sheet layers are change the failure mode from tensile rupture to IC debonding of CFRP sheets in RHSC continuous beams

2 . Increasing the number of CFRP layers reduced loss in stiffness of strengthened beams after yielding the tensile steel.

3. The deflection ductility index was decreased by increasing the number of CFRP layers.
4. The present nonlinear finite element model is a powerful tool and it can be provide the researchers with a lot of important information that cannot be supplied by the experimental test.

\section{REFERENCES}

[1]Akbarzadeh, H., Maghsoudi, A.A., "Experimental and analytical investigation of reinforced high strength concrete continuous beams strengthened with fiber reinforced polymer", Journal of Materials and Design Vol.31, 2010. P1130-1147.

[2]Arduini M, Nann A, Tommaso AD, Focacci F. Shear response of continuous RC beams strengthened with carbon FRP sheets. Non-metallic (FRP) reinforcement for concrete structures. In: Proceedings of the Third International Symposium (FRPRCS-3), Sapporo, Japan, October, vol. 1, 1997. p. 459-66.

[3] Khalifa A, Tumialan G, Nanni A, Belarbi A. Shear strengthening of continuous reinforced beams using externally bonded carbon fiber reinforced polymer sheets. In: Fourth International Sympo- sium on Fiber Reinforced Polymer Reinforcement for Reinforced Concrete Structures. American Concrete Institute; 1999. p. 995-1008.

[4] Grace NF, Soliman AK, Abdel-Sayed G, Saleh KR. Strengthening of continuous beams using fiber reinforced polymer laminates. In: Fourth International Symposium on Fiber Reinforced Polymer Reinforcement for Reinforced Concrete Structures. American Concrete Institute; 1999. p. 647-57.

[5] Tann DB, Delpak R. Shear strengthening of continuous reinforced concrete beams using externally bonded carbon fibre sheets. Concrete Communication Conference 2000, the 10th BCA Annual Conference on Higher Education and the Concrete Industry, 29-30 June, Birmingham, UK, 2000. p. 325-38.

[6] ACI Committee 440. Starte-of-the-art report on fiber reinforced plastic reinforcement for concrete structures, Report ACI 440R-96. Detroit, USA: American Concrete Institute; 1996.

[7] Concrete Society. Design guidance for strengthening concrete structures using fiber composite materials. Concrete Society Technical Report No. 55, 2000. 71p.

[8] Ashour AF, El-Refaie SA, Garrity SW. Flexural strengthening of RC continuous beams using CFRP laminates. Cement Concrete Composite. Vol. 26. 2004, p765-775

[9] El-Refaie SA, Ashour AF, Garrity SW. Sagging and hogging strengthening of continuous reinforced concrete beams using carbon fiberreinforced polymer sheets. ACI Structural Journal. Vol. 100, 2003, p446453.

[10] ANSYS, “ANSYS Help”, Release 11.0, Copyright 2006. 